\title{
Análise da acessibilidade em uma clínica gerontogeriátrica em Recife - PE: ênfase nos ambientes de livre acesso aos usuários
}

\author{
Ana Katharina Leite", Ana Karina Pessoa da Silva**
}

\section{Resumo}

O aumento do número de idosos na população mundial e a procura crescente dessa população pelos serviços de saúde tornam necessária a adequação do ambiente construído para promover um atendimento de qualidade, com conforto e segurança, apoiado na legislação vigente no país. Desta forma, foi realizada uma análise dos ambientes de livre acesso de uma clínica gerontogeriátrica em Recife, considerando que, sobretudo, no espaço em questão os clientes devem circular livremente, dependendo o mínimo possível de apoio, supervisão ou manejo dos profissionais de saúde. Para tanto, foi utilizada como parâmetro a NBR 9050/04, que trata da acessibilidade a edificações, mobiliários, equipamentos e espaços urbanos. Como resultado, obteve-se que mais de metade da clínica encontra-se acessível, no entanto não possui nenhum ambiente que atenda a todos os requisitos, em especial o hall de entrada e os sanitários, que apresentaram maior índice de inadequação. O cum- primento da acessibilidade se faz necessário para oferecer as condições mínimas de infraestrutura para um atendimento de qualidade, preconizando em seu próprio espaço garantias de segurança e adequação e, consequentemente, a possibilidade de autonomia e independência aos idosos.

Palavras-chave: Acessibilidade. Envelhecimento. Ergonomia.

\section{Introdução}

O aumento da população de idosos é um fenômeno demográfico irrefutável e amplamente discutido na literatura especializada. Dados estatísticos mostram que nos próximos vinte anos o número de idosos no Brasil excederá trinta milhões, o que representará aproximadamente $13 \%$ da população. Atualmente, dentre as capitais brasileiras que apresentam maior proporção de idosos estão, respec-

* Terapeuta ocupacional pela Universidade Federal de Pernambuco. Especialista em Tecnologia Assistiva pela Universidade Católica de Pernambuco. Mestra em Design e Ergonomia pela Universidade Federal de Pernambuco. Endereço para correspondência: Rua José Tavares da Mota, 90, bairro Iputinga, Recife - PE, CEP 50.670-340. E-mail: anakleite@gmail.com

** Terapeuta ocupacional pela Universidade Federal de Pernambuco. Especialista em Tecnologia Assistiva pela Universidade Federal de Minas Gerais. Especialista em Ergonomia pela Universidade Federal de Pernambuco. Mestra em Design e Ergonomia pela Universidade Federal de Pernambuco.

$\rightarrow$ Recebido em setembro de 2008 - Avaliado em agosto de 2009.

$\rightarrow$ doi:10.5335/rbceh.2009.043 
tivamente, Rio de Janeiro, Porto Alegre e Recife. (IBGE, 2000).

Essa realidade demográfica deve ser considerada no planejamento e na adaptação dos vários serviços que atendem a essa população, pois o novo perfil é de uma população envelhecida, cujas peculiaridades psicossociais e biológicas devem ser consideradas. Isso se reflete também nos serviços de saúde, pois o segmento idoso é o que menos tem acesso a esse tipo de serviço, embora seja o que apresenta os piores indicadores de saúde e de capacidade funcional. (NERI 2007).

A capacidade funcional de um indivíduo reflete competência em se engajar nas atividades de vida diária (AVD) e instrumentais de vida diária (AIVD), o que depende da relação entre as habilidades (neuromusculoesqueléticas, cognitivas e psicossociais) e o contexto em que está inserido. (FIEDLER; PERES, 2008; NERI, 2001).

A Organização Mundial de Saúde, por meio da Classificação Internacional de Funcionalidade, Incapacidade e saúde (CIF), reconhece que a deficiência é resultado não da presença de incapacidades, mas da falta de adequação do ambiente às capacidades residuais dos indivíduos. (CIF, 2003).

Nesse contexto, percebe-se que o planejamento e a adequação dos ambientes são determinantes para o desempenho eficaz e satisfatório nas tarefas que compõem a rotina das pessoas, ou seja, nas atividade de autocuidado, trabalho e lazer.

Reed (1984) e Mosey (1986) (apud HAGEDORN, 2007) esclarecem que o termo "ambiente" é amplo e pode ser empregado para referir os aspectos físicos ou socioculturais dos contextos. Este estudo se deterá aos aspectos físicos do ambiente, mais especificamente na acessibilidade, mas reconhece que a performance satisfatória do idoso depende não apenas da acessibilidade, mas de elementos físicos e psicossociais, como a integridade das funções e estruturas do corpo e a oportunidade/estimulação por familiares/responsáveis da participação social nos contextos onde as atividades cotidianas são desempenhadas.

No que diz respeito à legislação, as normas gerais e os critérios básicos para a promoção da acessibilidade para pessoas portadoras de deficiência e mobilidade reduzida estão estabelecidos na lei $n^{\circ}$ 10.098/2000, cujo capítulo IV trata mais especificamente da acessibilidade nos edifícios públicos ou de uso coletivo, como é o caso dos serviços de saúde para a população idosa.

A adequação dos serviços destinados à população idosa é prevista na lei $\mathrm{n}^{0}$ 10.741/2003, que dispõe, dentre outras questões, sobre o Estatuto do Idoso. O capítulo II, parágrafo único, deste documento regulamenta que as entidades de atendimento ao idoso devem oferecer instalações físicas em condições adequadas à salubridade, higiene e segurança.

$\mathrm{Na}$ perspectiva do ambiente construído, não há um parâmetro difundido notadamente desenvolvido para idosos (embora no estado de São Paulo exista uma norma para planejamento de casas de repouso e similares) Assim, este ajustamento é orientado pela NBR 9050/2004 da Associação Brasileira de Normas Técnicas, que trata da acessibilidade a 
edificações, mobiliários, equipamentos e espaços urbanos. (MELLO; PERRACINI, 2005).

A relevância dessa adequação do ambiente é proporcionar um espaço amigável para todos os usuários, incluindo os idosos, ou seja, garantir por meio do acesso a possibilidade de máxima autonomia e independência. $\mathrm{O}$ cumprimento dessa norma proporciona, ainda, segurança, conforto e maior eficácia para os profissionais envolvidos na prestação de serviços aos usuários da terceira idade, assim como para os acompanhantes.

No entanto, o que se percebe são ambientes sendo desenvolvidos muito mais com preocupação estética que com o conceito de design universal, segundo o qual os ambientes devem permitir que qualquer pessoa, independentemente do estado funcional, possa utilizá-lo plenamente. Logo, a aplicação da NBR 9050/2004 tem sido desconsiderada no planejamento e adaptação dos ambientes, tornando o acesso seletivo.

Assim, o presente estudo objetiva apresentar a análise da acessibilidade de um serviço de atendimento a idosos numa clínica multidisciplinar de profissionais de saúde, verificando a adequação do espaço construído aos usuários.

\section{Materiais e método}

A pesquisa trata-se de um estudo de caso de caráter descritivo, realizado em uma clínica gerontogeriátrica, localizada no bairro Casa Forte, na cidade do Recife.

Para fundamentação teórica foi realizada pesquisa bibliográfica em fontes dos últimos cinco anos nas línguas portu- guesa, inglesa e espanhola, cujas fontes foram livros, bases de dados (periódicos capes), manuais e revistas especializadas e anais de congresso. Os descritores pesquisados foram envelhecimento, acessibilidade, design universal, ergonomia, e gerontotecnologia.

A avaliação da instituição em questão foi realizada tendo como parâmetro técnico a NBR 9050/2004, que trata da acessibilidade a edificações, mobiliários, espaços e equipamentos urbanos.

A norma em questão possui nove capítulos com suas subseções, dentre os quais foram utilizados cinco e, destes, cinquenta subseções. Os capítulos empregados neste estudo foram: parâmetros antropométricos; comunicação e sinalização; acessos e circulação; sanitários e vestiários e mobiliário. As subseções de cada capítulo foram selecionadas de acordo com os espaços e mobiliários presentes na instituição. Essas subseções compuseram os cinquenta itens que compõem o checklist para a avaliação de cada espaço da clínica.

Para a realização deste estudo foram analisados os espaços que os clientes usam antes e depois das consultas, por se entender que nesses ambientes os clientes devem circular livremente, sem depender do apoio, supervisão ou manejo dos profissionais de saúde, ou seja, os espaços devem ser acessíveis. Dessa forma, os ambientes avaliados quanto a sua acessibilidade foram hall de entrada, sala de recepção, corredor e os sanitários.

$\mathrm{O}$ checklist foi dividido em cinco partes, uma parte para cada cômodo; em cada uma foram descritas as subseções da NBR 9050/2004 selecionadas ante- 
riormente. Assim, foi criado o roteiro dos itens que deveriam ser analisados e das medidas propostas para cada espaço, bem como para o mobiliário presente no mesmo. No total foram 101 itens avaliados, sendo 19 em cada sanitário, 24 no hall de entrada, 16 na sala de recepção e nove no corredor que dá acesso aos sanitários e consultórios.

A análise foi feita em duas visitas nos horários de funcionamento da clínica e todas as medidas foram orientadas pelo checklist, conferidas e, em seguida, comparadas com o recomendado nas NBR 9050/2004.

\section{Resultados e discussão}

A relevância do ambiente para a qualidade de vida do idoso vem sendo cada vez mais discutida e pesquisada no meio científico. Já em 1983, Lawton recomendava ambientes amigáveis para essa parcela da população, afirmando que a oferta de recursos físicos e psicossociais de natureza compensatória pode favorecer a saúde física, a funcionalidade e o bem-estar psicológico de idosos fragilizados, incapacitados e dependentes. (PRADO; PERRACINI, 2007).

Pesquisas recentes, como a de Cattelan et al. (2007), mostram a relevância do planejamento e da adaptação de ambientes favoráveis para idosos, embora a maioria ainda sejam estudos exploratórios, com pouca consistência metodológica.

Nesse contexto, surgiu uma disciplina voltada ao estudo das variáveis do ambiente e sua relação com o bem-estar físico, psicológico e emocional do idoso, a gerontologia ambiental, definida por
Tomasini (2005) como área da gerontologia que se concentra na descrição, explicação e modificação (ou otimização) das relações entre idosos e seus contextos socioespaciais.

Para Perracini (2002, p. 2) um dos aspectos básicos relacionados ao planejamento de ambientes para a terceira idade é a acessibilidade, definida na NBR 9050/04 como "possibilidade e condição de alcance, percepção e entendimento para a utilização com segurança e autonomia de edificações, espaço, mobiliário, equipamento urbano e elementos".

Ao viabilizar o uso de maneira simples e fácil dos múltiplos elementos do ambiente, está se fazendo acessibilidade. É o que preconizam Alonso et al. (2005), esclarecendo que os elementos arquitetônicos não são os únicos nem os mais relevantes em projetos de acessibilidade. Os autores esclarecem ainda a relevância que deve ser dada ao planejamento e à adaptação dos ambientes, pois, tal como defende a CIF (2003), esses podem ser incapacitantes, sugerindo que a disfunção está no sujeito, não no meio que o cerca.

A adaptação dos serviços de saúde não pode ser encarada de forma diferente, uma vez que a demanda de usuários idosos é cada vez mais significativa. (PEIXOTO et al., 2004).

Para Iida (2005) o usuário do ambiente e as atividades desenvolvidas determinam como deve ser o espaço físico. Considerando uma clínica cujos serviços são voltados para idosos, devemse apreciar as características do processo de senescência, com alterações sensoriais e neuromusculoesqueléticas, dentre outras, que têm implicações significativas na interação com o ambiente. 
Ao analisar o acesso da clínica em questão, utilizou-se como instrumento o checklist elaborado (Quadro 1) com base na NBR 9050/2004, que considera as di- versas condições de mobilidade (com ou sem dispositivos assistivos) de percepção do ambiente.

Quadro 1 - Checklist utilizado para a avaliação da acessibilidade.

\begin{tabular}{|c|c|c|}
\hline Ambientes / Subseções na NBR 9050/04 & $\begin{array}{l}\text { Adequado à } \\
\text { norma }\end{array}$ & $\begin{array}{l}\text { Inadequado } \\
\text { à norma }\end{array}$ \\
\hline \multicolumn{3}{|l|}{ Hall de entrada } \\
\hline Largura para deslocamento em linha reta para pessoa com cadeira de rodas. & - & \\
\hline Área de manobra com deslocamento & - & \\
\hline Área de manobra sem deslocamento & - & \\
\hline $\begin{array}{l}\text { Inclinação da rampa da entrada p sala da recepção (largura e altura do } \\
\text { desnível) }\end{array}$ & - & \\
\hline Telefone instalado suspenso e com altura livre & - & \\
\hline Parte operacional superior do telefone para cadeirante & & * \\
\hline Telefone com amplificador de sinais & & * \\
\hline Área de aproximação frontal e lateral do telefone & & * \\
\hline Comprimento do fio do telefone & - & \\
\hline Altura do acionamento do bebedouro & - & \\
\hline Área de aproximação frontal do bebedouro & & * \\
\hline Altura do porta-copo & - & \\
\hline Altura livre mesa & - & \\
\hline Aproximação frontal & & * \\
\hline Área livre para manobra & - & \\
\hline Altura da mesa & - & \\
\hline Altura e profundidade cadeira 1 & - & \\
\hline Altura e profundidade cadeira 2 & & * \\
\hline Vão livre mínimo de $0,80 \mathrm{~m}$ e altura mínima de 2,10 m & & * \\
\hline $\begin{array}{l}\text { Condição de serem abertas com um único movimento, maçanetas do tipo } \\
\text { alavanca, instalação das maçanetas a uma altura entre } 0,90 \mathrm{~m} \text { e } 1,10 \\
\mathrm{~m} \text {, revestimento resistente a impactos na parte inferior quando em rotas } \\
\text { acessíveis (altura de } 0,40 \mathrm{~m} \text { ) a partir do piso }\end{array}$ & & * \\
\hline $\begin{array}{l}\text { Portas de locais de saúde devem ter associado à maçaneta um puxador } \\
\text { horizontal (distância de } 10 \mathrm{~cm} \text { da dobradiça com comprimento igual à metade } \\
\text { da largura da porta) }\end{array}$ & & * \\
\hline Superfície regular, firme, padrão único, antiderrapante & - & \\
\hline Piso tátil de alerta & & * \\
\hline Não utilizar tapetes em rotas acessíveis & - & \\
\hline \multicolumn{3}{|l|}{ Sala de recepção } \\
\hline Largura para deslocamento em linha reta para pessoa com cadeira de rodas & - & \\
\hline Área de manobra com deslocamento & & * \\
\hline Área de manobra sem deslocamento & & * \\
\hline Espaço para cadeira de rodas estacionada & & * \\
\hline Área de circulação máxima (distância entre a mesa e as cadeiras de espera) & - & \\
\hline
\end{tabular}


Cont.

Área de circulação mínima (entre as cadeiras)

Aproximação frontal à mesa

Altura e profundidade da cadeira

Altura da mesa

Altura livre da mesa

Vão livre mínimo de $0,80 \mathrm{~m}$ (com duas folhas, uma delas ao menos com essas dimensões), altura mínima de 2,10 m (com duas folhas, uma delas ao menos com essas dimensões)

Condição de serem abertas com um único movimento, maçanetas do tipo alavanca, instalação das maçanetas a uma altura entre 0,90 m e 1,10

$\mathrm{m}$, revestimento resistente a impactos na parte inferior quando em rotas acessíveis (altura de $0,40 \mathrm{~m}$ ) a partir do piso

Portas de locais de saúde devem ter associado à maçaneta um puxador horizontal (distância de $10 \mathrm{~cm}$ da dobradiça com comprimento igual à metade da largura da porta)

Superfície regular, firme, padrão único, antiderrapante

Piso tátil de alerta

Não utilizar tapetes em rotas acessíveis

Corredor para consultórios

Comprimento inicial

Área para manobra com deslocamento

Área para manobra sem deslocamento

Superfície regular, firme, padrão único, antiderrapante

Piso tátil de alerta

Não utilizar tapetes em rotas acessíveis

Sanitário masculino e feminino

Localiza-se em rota acessível

Áreas de transferência diagonal, lateral e perpendicular de 1,20 m de comprimento e $0,80 \mathrm{~m}$ de largura

Barras diâmetro entre 3 e $4,5 \mathrm{~cm}$ e distância e $4 \mathrm{~cm}$ da face interna à parede onde está fixada

Barra horizontal junto à bacia sanitária na lateral e no fundo, comprimento de 0,80 $\mathrm{m}$ e altura de $0,75 \mathrm{~m}$, distância entre o eixo da bacia (linha média) e a face externa da barra é de $0,40 \mathrm{~m}$. Da face externa da bacia à linha de fixação anterior da barra lateral a distância é de $0,50 \mathrm{~cm}$

A bacia deve ter distância de 0,43 $\mathrm{m}$ a 0,45 $\mathrm{m}$ do piso acabado (da borda superior da bacia, sem assento). Altura máxima da bacia com o assento é de $0,46 \mathrm{~m}$

Papeleira que avance até $0,10 \mathrm{~m}$ deve estar a uma altura de 0,50 m a 0,60 m do piso acabado, a uma distância de $0,15 \mathrm{~m}$ da linha que representa a face externa da bacia

Acionamento da descarga $1,00 \mathrm{~m}$ do piso acabado

A borda superior do lavatório deve estar de $0,78 \mathrm{~m}$ a 0,80 $\mathrm{m}$ do piso acabado, altura livre mínima de $0,73 \mathrm{~m}$, cifão e tubulação a $0,25 \mathrm{~m}$ da face externa do lavatório com proteção do tipo coluna

Torneira acionada por alavanca, o comando da torneira deve estar a 0,50 m da face externa do lavatório

Barras de apoio junto ao lavatório 
Cont.

Borda inferior do espelho 0,90 m, borda superior do espelho máximo de $1,80 \mathrm{~m}$

Saboneteira de $0,80 \mathrm{~m}$ a $1,20 \mathrm{~m}$ do piso acabado

Toalheira horizontal na face interna da porta

Vão livre mínimo de $0,80 \mathrm{~m}$ (com duas folhas, uma delas ao menos com

essas dimensões), altura mínima de 2,10 $\mathrm{m}$ (com duas folhas, uma delas ao

menos com essas dimensões)

Condição de serem abertas com um único movimento, maçanetas do tipo

alavanca, instalação das maçanetas a uma altura entre 0,90 m e 1,10

$\mathrm{m}$, revestimento resistente a impactos na parte inferior quando em rotas

acessíveis (altura de $0,40 \mathrm{~m}$ ) a partir do piso

Portas de sanitários e de locais de saúde devem ter associados à maçaneta

um puxador horizontal (distância de $10 \mathrm{~cm}$ da dobradiça com comprimento

igual a metade da largura da porta)

Superfície regular, firme, padrão único, antiderrapante

Piso tátil de alerta

Não utilizar tapetes em rotas acessíveis

Com relação à autonomia e segurança, independentemente de idade, observou-se que a instituição dos 84 itens avaliados apresentou aproxima- damente $55 \%$ do ambiente acessível e $45 \%$ com acessibilidade comprometida, conforme Tabela 2.

Tabela 2 - Resultado em porcentagem da acessibilidade de cada ambiente da clínica.

\begin{tabular}{cccc}
\hline Ambiente & Itens avaliados & $\begin{array}{c}\text { Adequação } \\
\left(\mathrm{n}^{\circ} / \%\right)\end{array}$ & $\begin{array}{c}\text { Inadequação } \\
\left(\mathrm{n}^{\circ} / \%\right)\end{array}$ \\
\hline Hall de entrada & 24 & $14(58,33 \%)$ & $10(41,67 \%)$ \\
Sala de recepção & 16 & $8(50 \%)$ & $8(50 \%)$ \\
Corredor & 6 & $4(66,66 \%)$ & $2(33,34 \%)$ \\
Sanitários & 38 & $20(52,63 \%)$ & $18(47,37 \%)$ \\
Total & 84 & $46(54,76 \%)$ & $38(45,24 \%)$ \\
\hline
\end{tabular}

O espaço avaliado que apresentou maior inadequação foi o hall de entrada, seguido pelos sanitários. Esse resultado é relevante, uma vez que o hall é o ambiente por onde todos obrigatoriamente circulam para ter acesso ao restante da clínica, e o banheiro é, de acordo com Dekker et al. (2007), Stamato e Moraes (2007), um dos locais mais perigosos para idosos.

A seguir são apresentados os resultados das demais variáveis da acessibilidade da clínica, da seguinte forma: acessibilidade do piso e das portas da clínica, do hall de entrada, da sala de recepção, do corredor e dos sanitários.

Os cômodos avaliados encontram-se no mesmo pavimento. Todos possuem piso de cerâmica com superfície regular (sem desníveis de mais de $5 \mathrm{~mm}$ ), firme e estável. O piso é de um padrão misto, claro e escuro, o que, segundo a NBR 9050/2004, pode provocar sensação de tridimensionalidade e insegurança. Segundo Perracini (2002), isso ocorre 
em virtude da diminuição da noção de profundidade na terceira idade. A autora refere que, além de pisos desenhados serem inapropriados, também pode ocorrer desorientação em ambiente com monotonia de cores.

O revestimento de cerâmica em determinadas condições (molhado) torna-se perigoso por ficar escorregadio. Não há em todas as rotas acessíveis tapetes, tal como recomendado. Também não há sinalizações de alerta para os obstáculos suspensos, como extintores de incêndio e orelhão.

As situações supracitadas representam riscos para usuários idosos, uma vez que o envelhecimento leva a alterações no sistema nervoso, que se precipitam na lentidão do tempo de reação, do julgamento e do planejamento do ato motor e dos mecanismos antecipatórios. Assim, impedir obstáculos nas áreas de circulação (fios e tapetes) e a conservação do piso (sempre seco e íntegro) devem ser considerados. (PERRACINI, 2002).

$\mathrm{O}$ hall de entrada tem área total de 29,25 $\mathrm{m}^{2}$ (Fig. 1a). O acesso ocorre por um portão de ferro (Fig. 1b) com duas portas, cujas dimensões de largura e altura estão fora dos padrões (altura 2,04 m, sendo a altura mínima ideal $2,10 \mathrm{~m}$; a largura das duas folhas do portão é de $0,96 \mathrm{~m}$, sendo largura ideal para passagem concomitante de um pedestre e um cadeirante $1,20 \mathrm{~m}$ a $1,50 \mathrm{~m}$ ).

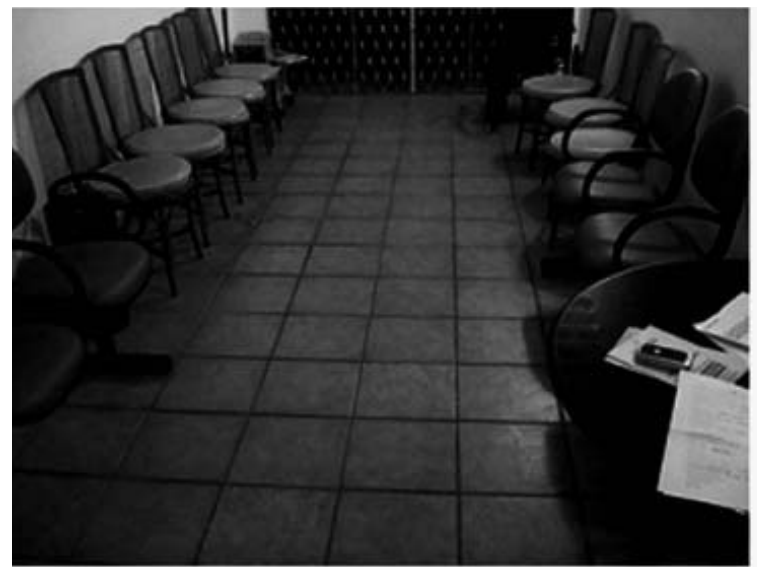

(a)

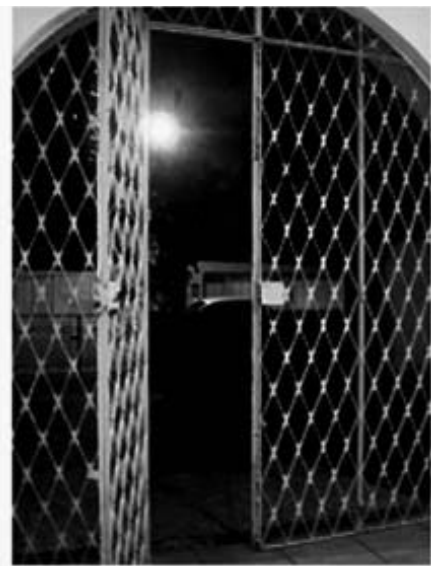

(b)

Figura 1 - Vista do hall de entrada a partir do portão de acesso.

Das duas folhas do portão que proveem acesso a esse ambiente, nenhuma é facilmente aberta e não há maçaneta. Por se tratar de um portão, possui aberturas próprias do seu design que deixam $o$ piso interno exposto às intempéries (chuva), o que pode representar risco de quedas aos usuários diretos, indiretos e profissionais do serviço.

O hall de entrada possui ainda área de circulação com largura de $1,55 \mathrm{~m}$, cuja dimensão é adequada para deslocamen- 
to em linha reta de um pedestre e um indivíduo em cadeira de rodas $(1,20$ a $1,50 \mathrm{~m}$ ). Essa dimensão em largura permite ainda manobra de cadeira de rodas com deslocamento de $90^{\circ}$ e $180^{\circ} \mathrm{e}$ sem deslocamento (rotação de $90^{\circ}=1,20$ $\mathrm{m} \times 1,20 \mathrm{~m}$; rotação de $180^{\circ}=1,50 \mathrm{~m} \times$ $1,20 \mathrm{~m}$; rotação de $360^{\circ}=$ raio de $1,50 \mathrm{~m}$ ).

O cômodo em questão possui ainda os seguintes mobiliários: telefone público, mesa, cadeiras e um bebedouro. $\mathrm{O}$ telefone público presente no hall de entrada é único na instituição, não possuindo amplificador de sinal ou transmissor de texto.
O telefone público está instalado à altura de $1,53 \mathrm{~m}$, sendo o ideal máximo de $1,20 \mathrm{~m}$ para a parte operacional superior (Fig. 2a). Não há telefone em altura adequada para uso por cadeirante ou com amplificador de sinal. Esse mobiliário permite aproximação frontal, mas não lateral, e possui altura livre inferior maior de $0,73 \mathrm{~m}$. O comprimento do fio é o adequado, de $0,75 \mathrm{~m}$; assim, permite aproximação de um cadeirante, mas não o acesso em razão de a altura de instalação ser inadequada (Fig. 2b).

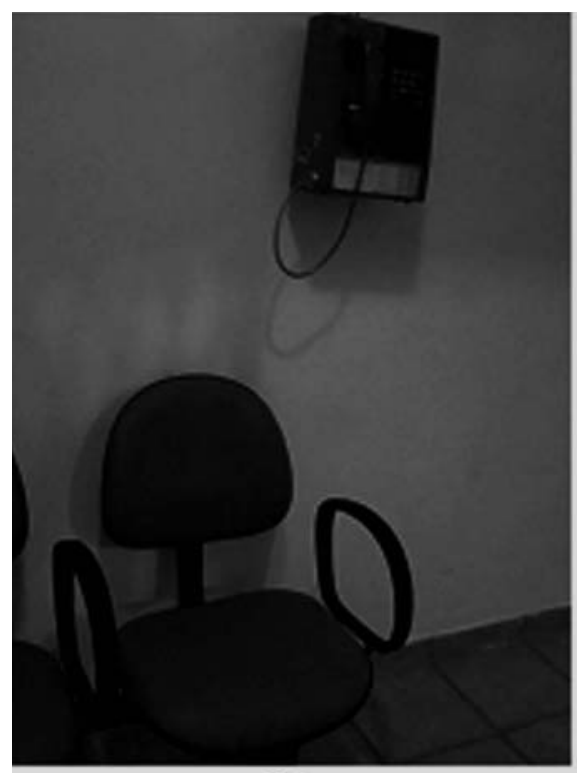

(a)

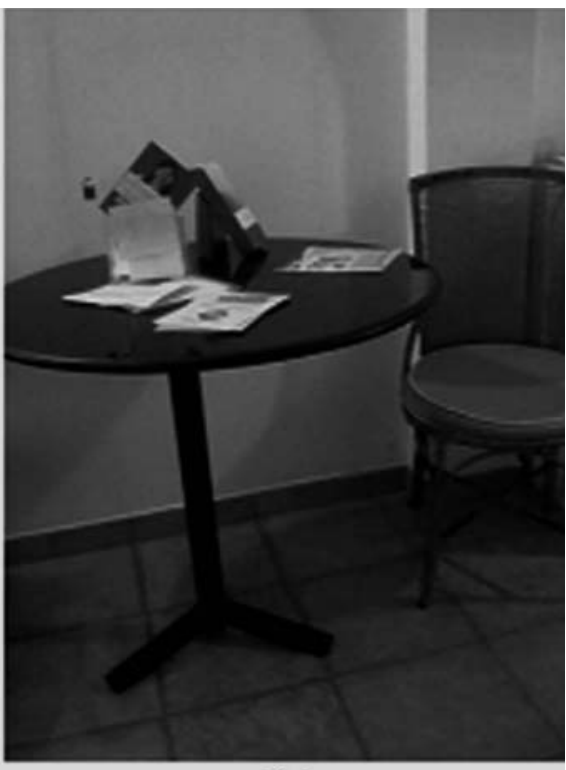

(b)

Figura 2 - Telefone público e mesa no hall de entrada.

A mesa presente no hall de entrada é próxima à rota acessível do cômodo e possui altura de $0,79 \mathrm{~m}$, sendo de altura livre $0,77 \mathrm{~m}$, o que está de acordo com a norma que preconiza altura ideal de 0,75 m a $0,85 \mathrm{~m}$ e altura livre ideal mínima de $0,73 \mathrm{~m}$. A dimensão para área de aproximação é de $0,43 \mathrm{~m}$ frontal, sendo o ideal de 0,5 m, o que dificultaria o uso da mesa por um cadeirante. Esse espaço permite manobra de cadeira de rodas. 
As cadeiras localizadas no hall são utilizadas tanto na mesa quanto distribuídas lado a lado ao longo do espaço, encostadas junto à parede. Tendo em vista que o assento em questão não é fixo, para fins de comparação foram utilizadas as medidas de conforto para alcance manual na posição sentada.

Nesse ambiente há dois tipos de cadeira, uma com altura de $0,4 \mathrm{~m}$ e outra com $0,44 \mathrm{~m}$. As medidas de profundidade são de $0,39 \mathrm{~m}$ e $0,45 \mathrm{~m}$, respectivamente. Tendo em vista o parâmetro antropométrico de $0,38 \mathrm{~m}$ a $0,43 \mathrm{~m}$ da fossa poplítea (parte posterior do joelho) até o piso, a altura é adequada, pois permite a descarga do peso sobre os pés e favorece a mudança de posição de sentado para de pé. No que concerne à profundidade do assento, o recomendado, de acordo com as dimensões tomadas como referência, é de $0,40 \mathrm{~m}$ a $0,51 \mathrm{~m}$, o que torna a medida de uma das cadeiras inadequada.

Em razão da sarcopenia (diminuição da força, potência e da flexibilidade muscular), o idoso pode ter dificuldade para se levantar de assentos baixos. (CALKINS; VLADUTIU, 2002).

Quanto ao bebedouro tipo garrafão, o acionamento está a uma altura de $0,84 \mathrm{~m}$ (ideal entre $0,80 \mathrm{~m}$ e $1,20 \mathrm{~m}$ para alcance manual), estando adequado (Fig. 3). O bebedouro não permite aproximação da cadeira de rodas por estar em um suporte que não possui altura livre inferior suficiente. O porta-copo, segundo a norma, deve também estar a uma altura confortável para alcance manual, estando a $0,79 \mathrm{~m}$, portanto adequado.

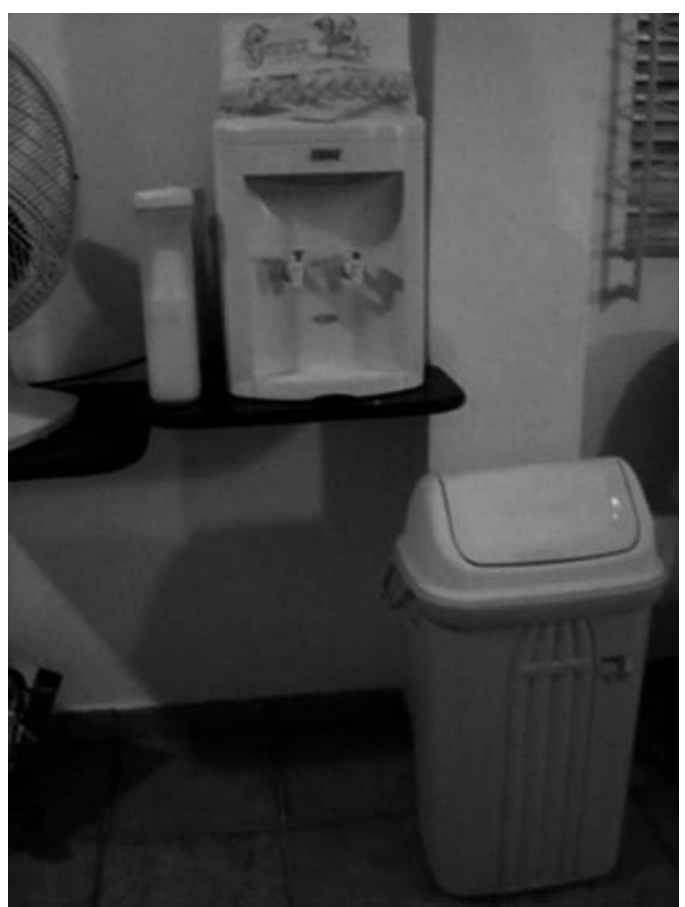

Figura 3 - Bebedouro tipo garrafão.

A relevância do mobiliário em alturas confortáveis pode compensar a diminuição da elasticidade e da amplitude de movimento que tornam o abaixar-se e a realização de movimentos amplos custosos. (CALKINS; VLADUTIU, 2002; PERRACINI, 2002).

No que diz respeito à sala de recepção (Fig. 4a e 4b), o acesso é feito por meio de uma rampa, o que está conforme a norma, pois o desnível é maior que $5 \mathrm{~mm}$. A inclinação da rampa é de $1,1 \%$, o que está adequado para rampas internas, cuja inclinação não pode ser superior a $2 \%$. 


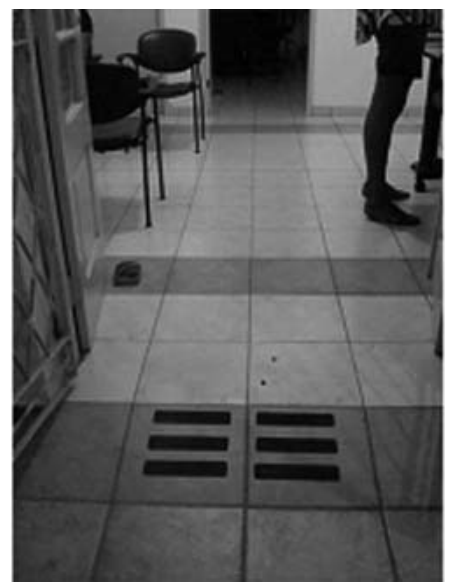

(a)

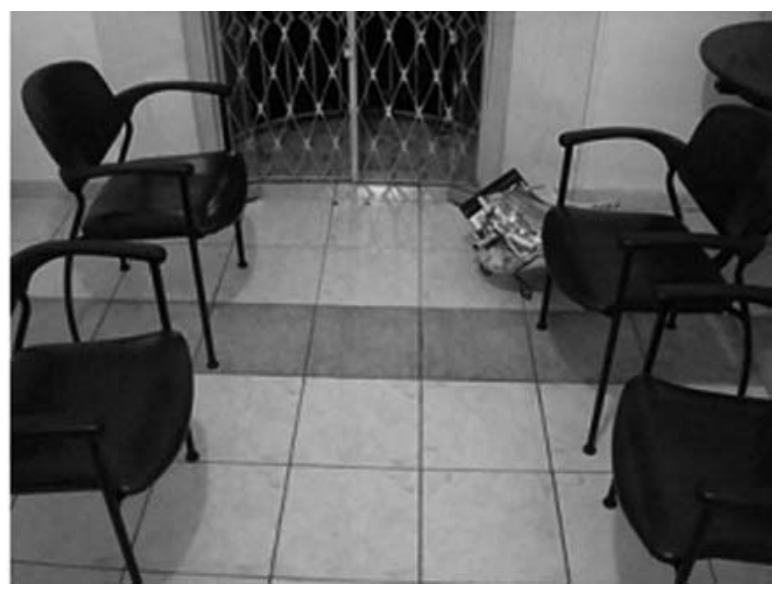

(b)

Figura 4 - Acesso à sala de recepção e área de deslocamento entre as cadeiras.

A porta de acesso à recepção possui as seguintes dimensões: $1,18 \mathrm{~m}$ de largura (as duas folhas) x 2,04 m de altura. Considerando a largura ideal para 0 tráfego de um pedestre e um cadeirante $(1,20 \mathrm{~m}$ a $1,50 \mathrm{~m})$, a porta não atende à medida normatizada, mas permite o acesso a um usuário com qualquer dispositivo de mobilidade. A altura, por sua vez, está pouco abaixo do mínimo recomendado, que é $2,10 \mathrm{~m}$. A facilidade de abrir não foi considerada, bem como a altura e o tipo da maçaneta e a presença de revestimento contra impacto, pois na dinâmica do serviço as duas folhas da porta ficam continuamente abertas.

Nesse ambiente o mobiliário encontrado é uma mesa de trabalho e cadeiras. Usando como parâmetro as medidas já mencionadas, observa-se que a mesa, com a altura de $0,81 \mathrm{~m}$, altura livre de $0,74 \mathrm{~m}$ e aproximação frontal de $0,34 \mathrm{~m}$, torna-se inadequada por não permitir aproximação frontal adequada (mínimo de $0,5 \mathrm{~m}$ ). A cadeira presente neste am- biente tem 0,43 $\mathrm{m}$ de altura e 0,43 $\mathrm{m}$ de profundidade, o que atende à medida de conforto na postura sentada.

A área de circulação entre a mesa da recepção e as cadeiras é de 1,26 m. O ambiente em questão faz parte da rota obrigatória para acesso aos consultórios; dessa forma, a área de circulação permite o deslocamento em linha reta de um cadeirante e um pedestre lado a lado. Essa dimensão também permite a manobra de acesso à mesa por um cadeirante, cujas medidas necessárias seriam 0,80 $\mathrm{m}$ de largura $\mathrm{x}$ 1,20 m de comprimento.

As cadeiras dispostas na sala de recepção deixam um corredor para circulação à frente delas de $0,85 \mathrm{~m}$, o que é adequado para deslocamento do cadeirante em linha reta, mas não permite manobra. Não há na sala de recepção um espaço reservado para cadeira de rodas, que não interfira na área de circulação.

O corredor que proporciona o acesso aos sanitários e aos consultórios tem largura irregular, tendo 0,96 m 
de largura inicial, o que permite deslocamento em linha reta de cadeira de rodas, e $2,67 \mathrm{~m}$ no restante do espaço, o que também permite manobra com e sem deslocamento. Como o corredor possui extensão de $3,33 \mathrm{~m}$, está adequado, pois, segundo a NBR 9050/2004, esses espaços devem ter " 0,90 m para corredores de uso comum com extensão até 4,00 m”. (p. 50).

A clínica possui dois sanitários (masculino e feminino) de uso comum aos clientes, acompanhantes e profissionais. Ambos os sanitários foram planejados com as mesmas medidas, um projetado como espelho do outro.

Não há sanitário projetado com vaso sanitário infantil para ser usado por crianças ou pessoas com baixa estatura. A NBR 9050/2004 também recomenda sanitário familiar/unissex para o uso de cadeirantes que tenham acompanhantes de sexo diferente.

Os sanitários analisados localizamse em rota acessível. As portas possuem maçanetas do tipo alavanca a $1,06 \mathrm{~m}$ do piso (ideal entre $0,90 \mathrm{~m}$ e $1,10 \mathrm{~m}$ ) e dimensões de $0,88 \mathrm{~m}$ de largura x 2,10 m de altura, estando adequadas. No entanto, não apresentam revestimento de impactos na parte inferior (necessário em rotas acessíveis), bem como puxador nas faces externa e interna.

Ambos os sanitários não possuem áreas de transferências diagonal, lateral e perpendicular, necessárias para a passagem do cadeirante à bacia sanitária. São necessárias para tanto áreas livres com dimensões de $0,80 \mathrm{~m}$ de largura e $1,20 \mathrm{~m}$ de comprimento.

Em razão do público alvo da instituição, idosos, a instalação de um dispositi- vo de sinalização de emergência ao lado da bacia (a 0,40 $\mathrm{m}$ do piso acabado) seria interessante para acionamento em caso de quedas ou qualquer outra situação de urgência. Este dispositivo, pela NBR 9050/2004, é obrigatório em caso de banheiros acessíveis isolados, ou seja, fora das áreas de circulação principal.

As barras presentes nos sanitários obedecem à recomendação de diâmetro entre $3 \mathrm{~cm}$ e $4,5 \mathrm{~cm}$ e distância mínima de $4 \mathrm{~cm}$ da face interna da barra à parede onde está fixada (distância encontrada: $9,5 \mathrm{~cm}$ ). No entanto, cada banheiro possui apenas uma barra inclinada ao lado do sanitário, sendo recomendada barra horizontal na lateral e no fundo junto à bacia.

A presença de barras em sanitários de idosos foi estudada por Dekker et al. (2007), os quais concluíram que para essa população é mais confortável o uso das barras verticais, sendo a aceitação destas similares tanto paralelas à bacia sanitária quando ao fundo.

As dimensões de comprimento e distância do piso acabado também estão inadequadas, sendo as encontradas: $32 \mathrm{~cm}$ de comprimento (recomendado: $80 \mathrm{~cm}$ ); altura $70,5 \mathrm{~cm}$ do ponto de fixação mais baixo da barra inclinada e $72 \mathrm{~cm}$ do ponto de fixação mais elevado (recomendado: pontos de fixação à altura de $75 \mathrm{~cm}$ ).

A NBR 9050/2004 estabelece ainda que a distância entre o eixo (linha média) do vaso e a face externa da barra deve ser de $40 \mathrm{~cm}$, e o encontrado foi $29 \mathrm{~cm}$; a distância da linha imaginária traçada da face externa da bacia à linha de fixação anterior da barra a distância deve 
ser de $50 \mathrm{~cm}$, no entanto não havia essa distância, ficando as linhas na mesma sobrepostas.

Quanto às bacias sanitárias (Fig. 5a), a altura normatizada é de $43 \mathrm{~cm}$ a 45 $\mathrm{cm}$ do piso acabado, com altura máxima de $46 \mathrm{~cm}$ da bacia com assento ao piso. A distância encontrada sem assento foi de $37 \mathrm{~cm}$ e com assento $39 \mathrm{~cm}$.

A papeleira (Fig. 5c), por avançar $10 \mathrm{~cm}$ da parede, deve estar a uma altura de $50 \mathrm{~cm}$ a $60 \mathrm{~cm}$ do piso, e a medida encontrada foi esta última. A distância da papeleira ao vaso deve ser de $15 \mathrm{~cm}$, sendo encontrado o dobro, $30 \mathrm{~cm}$.

$\mathrm{O}$ acionamento de ambas descargas, que deveriam estar a $1 \mathrm{~m}$ do piso, está a 1,15 m. Quanto ao lavatório (Fig. 5b), não possui barras, como o recomendado; a borda superior, que deveria estar de $0,78 \mathrm{~m}$ a $0,80 \mathrm{~m}$, encontra-se a $0,87 \mathrm{~m}$, com altura livre mínima de $0,73 \mathrm{~m}$, sendo o visto $0,65 \mathrm{~m}$. O sifão e a tubulação do lavatório devem estar com proteção do tipo coluna, que não foi encontrada, e a uma distância mínima de $0,25 \mathrm{~m}$ da face externa do lavatório, sendo a medida presente de $0,29 \mathrm{~m}$, estando de acordo. Outra variável de acordo com a norma no lavatório foi a torneira, que tem o acionamento por alavanca, e o comando, que deve estar a uma distância máxima de $0,50 \mathrm{~m}$ da face externa do lavatório, encontra-se a $0,42 \mathrm{~m}$.

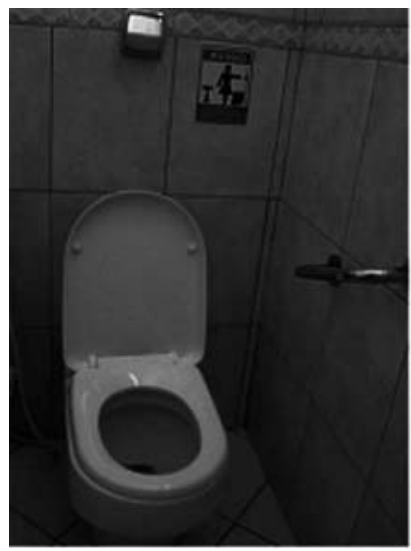

(a)

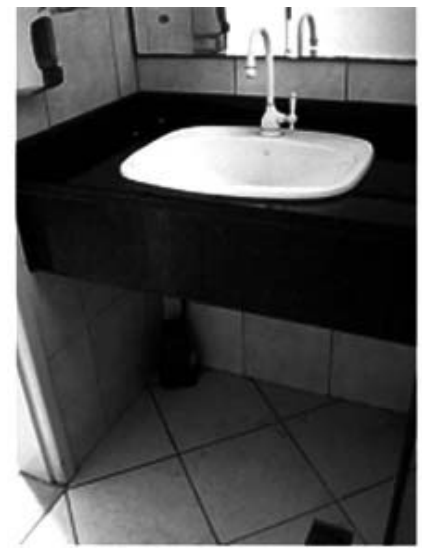

(b)

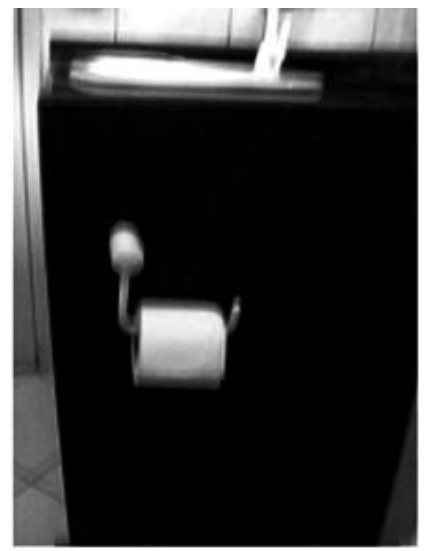

(c)

Figura 5 - Área da bacia sanitária, do lavatório e da papeleira ao lado do lavatório.

Os acessórios presentes em ambos os sanitários foram espelhos, saboneteiras e toalheiros. Os espelhos têm bordas inferiores a $1,05 \mathrm{~m}$ e superiores a 2,07 $\mathrm{m}$ do piso acabado, quando o recomendado é $0,90 \mathrm{~m}$ para borda inferior e 1,80 m para borda superior. Os demais acessórios devem estar dentro da faixa de alcance de $0,80 \mathrm{~m}$ e $1,20 \mathrm{~m}$, sendo as alturas encontradas: saboneteira a 1,08 $\mathrm{m}$ e toalheiro a $1,37 \mathrm{~m}$.

O espaço da clínica avaliado não possui nenhum tipo de sinalização (visual ou tátil) que oriente em relação à 
disposição dos ambientes cujas funções são definidas (sanitários, consultórios, rotas de fuga etc.).

Nos sanitários (Fig. 6a) há sinalização complementar visual (Fig. 6b), indicando os sanitários feminino e masculino, mas estes não estão adequados, tendo em vista que, como a proposta do banheiro é ser acessível, isto não está indicado.

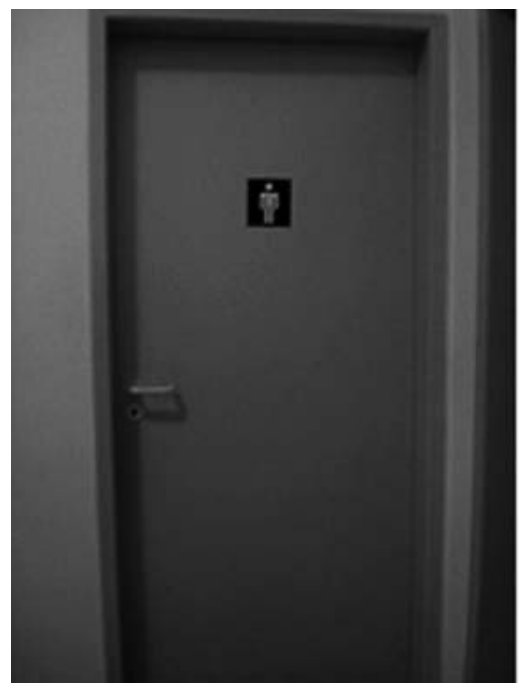

(a)

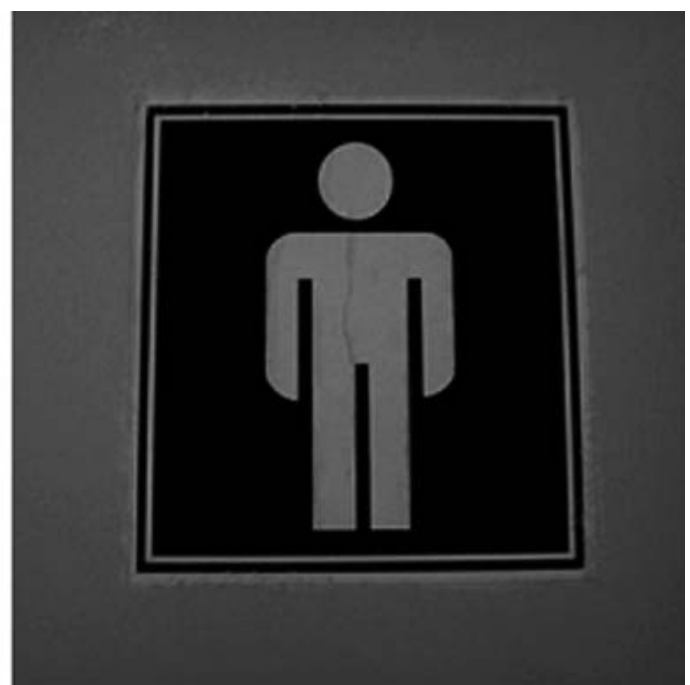

(b)

Figura 6 - Porta de acesso ao sanitário com respectiva sinalização.

A legibilidade dessas sinalizações não está comprometida no que diz respeito à variável iluminação, que possui boa qualidade. Segundo a NBR 9050/2004, a iluminação, o acabamento fosco, o contraste da sinalização com o entorno (cor da porta) não prejudicam a compreensão da informação (p. 22).

$\mathrm{O}$ desenho das figuras possui contornos fortes e bem definidos, simples na forma e com poucos detalhes; forma fechada, completa, com continuidade e simetria. A dimensão também está adequada, $15 \mathrm{~cm}$ x $15 \mathrm{~cm}$, considerando distância máxima de $30 \mathrm{~m}$ (o corredor para o qual a porta fica voltada possui 2,67 m de largura).

\section{Conclusão}

A análise da acessibilidade dos ambientes de livre acesso da clínica gerontogeriátrica estudada apontou que possui, aproximadamente, $55 \%$ do ambiente de livre acesso ao usuário acessível, ou seja, a maior parte do espaço construído está de acordo com NBR 9050/2004. No entanto, é uma porcentagem que alerta para a necessidade de investimento na adequação.

O estudo demonstrou que não há nenhum ambiente de livre acesso totalmente acessível, o que limita o uso às pessoas com quaisquer deficiências, inclusive aos 
usuários idosos, que, além das alterações advindas do processo de senescência, podem estar com uma condição de saúde prejudicada que potencialize o prejuízo à interação com o ambiente.

Os cômodos que necessitam de maior investimento são o hall de entrada e o banheiro, considerando a falta do cumprimento das condições mínimas de disposição, dimensão do mobiliário e da presença de dispositivos assistivos (barras de apoio).

Todas as avaliações foram entregues à instituição, que está ciente da necessidade das modificações e adaptações necessárias.

O cumprimento da NBR 9050/2004 por meio da adequação da acessibilidade é apenas um dos recursos usados para garantir um serviço de qualidade, que neste caso beneficiará tanto os profissionais e cuidadores envolvidos, mas, sobretudo os usuários idosos, que têm garantido na legislação o direito ao atendimento em instalações físicas que ofereçam condições adequadas à salubridade, higiene e segurança.

Esta foi uma pesquisa inicial cuja ênfase foi no ambiente construído. Sabese, no entanto, que para complementar o diagnóstico a respeito da acessibilidade na referida clínica, segundo olhar da ergonomia, há a necessidade de se avaliarem as características e necessidades das pessoas usuárias do ambiente, ou seja, os idosos. Dessa forma, a presente pesquisa necessita de desdobramentos futuros para resultados mais específicos e globais.
Analysis of accessibility a gerontogeriatric clinic in Recife - PE: emphasis on the environment of free access to users

\section{Abstract}

The increase in the number of elderly in world population and increasing demand of the population by the health services necessitate the adequacy of the built environment to promote a quality of care and support in the existing legislation in the country. Thus, an analysis was performed of environments for free access to a geriatric clinic in Recife, whereas especially in the area concerned customers should move freely, depending on the lowest possible level of support, supervision or management of health professionals. For this was used as a parameter to NBR 9050/2004 which deals with accessibility to buildings, furniture, equipment and urban spaces. The result obtained was that more than half of the clinic is accessible, yet has no environment that meets all the requirements, in particular health, with a major index of inadequacy. The enforcement of accessibility is necessary to adhere to the minimum conditions of infrastructure for a high-quality care, advocating in their own space the possibility of autonomy and independence for the elderly.

Key words: Accessibility. Aging. Human engineering.

\section{Referências}

ALONSO, J. V. G. et al. Preguntame sobre accesibilidad y ayudas técnicas. Valência, Espanha: Instituto de Biomecánica de Valencia, 2005.

CALKINS, E.; VLADUTIU, A. O. Distúrbios musculoesqueléticos. In: DUTHIE, E. H.; KATZ, P. R. (Org.). 3. ed. Geriatria prática. Rio de Janeiro: Revinter, 2002. p. 415-429. 
CATTELAN, A. V. et al. Análise de uma instituição de longa permanência para idosos em Passo Fundo - RS. Revista Brasileira de Ciências do Envelhecimento Humano, Passo Fundo, v. 4, n. 2, p. 75-82, jul./dez. 2007.

CLASSIFICAÇÃO INTERNACIONAL DE FUNCIONALIDADE, INCAPACIDADE E SAÚDE - CIF. São Paulo: USP, 2003. p. 323.

DEKKER, D. et al. Hand supports to assist toilet use among the elderly. Applied Ergonomics, v. 38, n. 1, p. 109-118, 2007.

FIEDLER, M. M.; PERES, K. G. Capacidade funcional e fatores associados em idosos do Sul do Brasil: um estudo de base populacional. Caderno de Saúde Pública, Rio de Janeiro, v. 24, n. 2, p. 409-415, 2008.

HAGEDORN, R. Análise do ambiente e adaptação. In: - Ferramentas para a prática em terapia ocupacional: uma abordagem estruturada aos conhecimentos e processos centrais. São Paulo: Roca, 2007. p. 382-441.

INSTITUTO BRASILEIRO DE GEOGRAFIA E ESTATÍSTICA. IBGE, 2000. Disponível em: <www.ibge.gov.br>. Acesso em: 20 set. 2008.

BRASIL. Lei 10.098, de 19 de dezembro de 2000. Promoção de acessibilidade a pessoas com deficiências e moblilidade reduzida. Disponível em: <www.010.dataprev.gov.br>. Acesso em: 20 de set. 2008.

MELLO, M. A. F.; PERRACINI, M. R. Avaliando e adaptando o ambiente doméstico. In: DUARTE, Y. A. O.; DIOGO, M. J. D. (Org.). Atendimento domiciliar: um enfoque gerontológico. São Paulo: Atheneu, 2005. p. 187-199.

ASSOCIAÇÃO BRASILEIRA DE NORMAS TÉCNICAS. ABNT. NBR 9050/2004: Acessibilidade a edificações, mobiliários, espaços e equipamentos urbanos. Rio de Janeiro: ABNT, 2004.

NERI, A. L. Palauras-chave em gerontologia. São Paulo: Alínea, 2001.
NERI, A. L. Qualidade de vida na velhice e subjetividade. In: Qualidade de vida na velhice: enfoque multidisciplinar. São Paulo: Alínea, 2007. p. 13-59.

PEIXOTO, S. V. et al. Custo das internações hospitalares entre idosos brasileiros no âmbito do Sistema Único de Saúde. Epidemiologia e Serviços de Saúde - Revista do Sistema Único de Saúde do Brasil, Brasília, v. 13, n. 4, p. 239-246, 2004.

PERRACINI, M. R. Planejamento e adaptação do ambiente para pessoas idosas. In: FREITAS, E. V. de et al. Tratado de geriatria e gerontologia. Rio de Janeiro: GuanabaraKoogan, 2000. p. 798-807.

PRADO, A. R. A.; PERRACINI, M. R. A construção de ambientes favoráveis aos idosos. In: NERI, A. L. Qualidade de vida na velhice: enfoque multidisciplinar. São Paulo: Alínea, 2007. p. 221-229.

STAMATO, C.; MORAES, A. A visão de idosos cariocas sobre a segurança de banheiros domiciliares. In: CONGRESSO INTERNACIONAL DE PESQUISA EM DESIGN, 4, 2007, Rio de Janeiro. Anais... 4º Congresso Internacional de Pesquisa em Design. Rio de Janeiro: CCJF, 2007.

TOMASINI, S. L. V. Envelhecimento e planejamento do ambiente construído: em busca de um enfoque multidisciplinar. Revista Brasileira de Ciências do Envelhecimento Humano, Passo Fundo, v. 2, n. 1, p. 76-78, jan./jun. 2005. 